\title{
Racial differences in experimental pain sensitivity and conditioned pain modulation: a study of Chinese and Indians
}

\section{Tze Siong Ng}

Department of Rehabilitation, Physiotherapy Section, National

University Hospital, Singapore, Singapore
This article was published in the following Dove Press journal: Journal of Pain Research

Background: Substantial literature has demonstrated racial differences in pain perception and endogenous pain modulation is proposed to be a mechanism for the racial differences. Although Indians in Singapore reported higher pain severity than Chinese, the only study on racial difference in experimental pain response in Singapore did not find any difference between the two racial groups.

Purpose: The aim of this study was to investigate pain sensitivity and conditioned pain modulation in Chinese and Indians in Singapore.

Patients and methods: Sixty age-and sex-matched (30 Chinese 50\% female, 30 Indian, $50 \%$ female) healthy adults participated in this study. Pressure pain threshold, thermal pain threshold and cold pain tolerance were measured. Conditioned pain modulation, general selfefficacy and depression were also tested, in an attempt to assess endogenous pain inhibition and psychological presentation between the two groups.

Results: No difference in pain thresholds was found between the two groups. Indians demonstrated less cold pain tolerance and less efficacious conditioned pain modulation than Chinese. Conditioned pain modulation was a mediator between race and cold pain tolerance.

Conclusion: These findings of racial disparities in pain tolerance and endogenous pain inhibition could possibly contribute to the higher pain severity in Indians.

Keywords: pain tolerance, race, general self-efficacy

\section{Introduction}

Pain is considered to be an experience with sensory, cognitive and emotional components. ${ }^{1}$ Besides the biological basis of pain, cultural and social factors are also viewed as the foundation to the expression and treatment of pain. ${ }^{2}$ Race is a social categorization imposed on people related to physical appearance for the purpose of making hierarchical power-based distinctions in social relations. ${ }^{3}$ Experimental pain testing in healthy individuals helps to elucidate potential differences in pain perception, without being confounded by disease-specific factors and disparities in pain management present in clinical pain studies. ${ }^{4,5}$ Racial disparities in pain perception and response have been demonstrated, with most of the research conducted on African-Americans and Caucasians. ${ }^{67}$ African-Americans exhibit lower pain tolerance and higher unpleasantness ratings than Caucasians in experimental pain studies. ${ }^{6,7}$ Several studies have compared Caucasians with Asians such as Indian and Chinese. ${ }^{8-12}$ Asians generally demonstrated lower pain tolerances than Caucasians. ${ }^{11,12}$ The evidence for lower pain
Correspondence: Tze Siong $\mathrm{Ng}$ Department of Rehabilitation, National University Hospital, 5 Lower Kent Ridge Road, Singapore 119074, Singapore

Tel +6567725168

Fax +6567797740

Email Tze_Siong_NG@nuhs.edu.sg 
thresholds in Asians is inconsistent. ${ }^{7-9}$ These studies were performed on young adults; hence generalization of results to the entire adult population cannot be made.

Conditioned pain modulation (CPM) refers to reduced pain intensity perception for a test stimulus when also exposed to a painful conditioning stimulus. ${ }^{13}$ The measurement of CPM provides a model for studying endogenously mediated pain modulation. ${ }^{14}$ Six studies compared racial differences in CPM, with the majority comparing African-Americans and Caucasians. ${ }^{13-18}$ The findings were inconsistent and the existence of racial differences in CPM is inconclusive. ${ }^{6}$

Psychological factors and endogenous pain inhibitory response are suggested to be potential contributors to the racial differences across all stimulus modalities. ${ }^{7}$ According to Bandura's (1977) social-cognitive theory, self-efficacy refers to personal judgments of how well a person believes he can perform specific behaviors in particular situations. ${ }^{19}$ Whilst self-efficacy is a task-specific belief, general self-efficacy (GSE) is a relatively stable, trait-like, generalized competence belief in one's ability to deal effectively with a variety of stressful situations. ${ }^{20,21}$ GSE has cognitive, affective and motivational components $^{20}$ People with higher GSE were found to be healthier and socially better integrated after a stressful event than their low GSE counterparts. ${ }^{22}$ In a general adult population survey, compared to health self-efficacy, GSE was more strongly associated with psychological distress in participants regardless of pain status; GSE was also more strongly associated with disability in participants with chronic pain. ${ }^{23}$ GSE is studied in this study as it is a relatively stable belief which could potentially influence pain perception and response in experimental pain, a stressful situation.

Specific psychological factors seem to be associated with modality-specific CPM responses in healthy individuals. Heat-based CPM correlated with depression, but not anxiety and pain catastrophizing. ${ }^{24}$ Studies have demonstrated depression to be associated with greater clinical pain $^{25}$ and greater experimental pain sensitivity. ${ }^{26}$ On the contrary, a meta-analysis found depressed patients had higher experimental pain thresholds than controls, suggesting diminished pain. ${ }^{27}$ In a recent study on Asian Americans and Caucasian Americans with knee osteoarthritis, Asian Americans reported higher levels of depression. ${ }^{28}$ Mediational analysis demonstrated that the higher levels of depression in Asian Americans may contribute to their higher levels of clinical pain and experimental pain sensitivity. ${ }^{28}$ The complexity of the underlying psychosocial mechanism of pain warrants further investigation. Depression was assessed in view of its potential influence on experimental pain sensitivity and its association with heat-based $\mathrm{CPM}^{24}$ employed in this study.

Singapore is a multi-racial Asian society comprising of three major racial groups, namely, Chinese, Malay and Indian. In a national survey of Singaporean older adults, Indians reported greater pain severity compared to Chinese. ${ }^{29}$ Indians used the highest amount of morphine and reported the highest pain intensity after cesarean delivery, compared to Chinese and Malay. ${ }^{30}$ However, no difference between the three racial groups was found in experimental pain measuring only heat pain threshold. ${ }^{31}$ Further study using experimental pain measuring pain tolerance and CPM would give insight into the racial difference in pain intensity reported.

The objective of this cross-sectional study is to examine racial differences in pain thresholds, pain tolerance, CPM and psychological factors (GSE and depression) between healthy Chinese and Indian adults in Singapore.

\section{Materials and methods Participants}

A total of 60 healthy Chinese and Indian adults were recruited from hospital staff and the general public through poster advertisements in National University Hospital $(\mathrm{NUH})$, Singapore. The race of participants was through self-identification. Individuals with mixed parentage were excluded ie, parents of our participants were both Chinese, or both Indian. Participants in these two racial groups were age- and sex-matched. Inclusion criteria ensured that all participants were in good health, no prior history of pain requiring treatment or psychiatric disorders. Female participants were not pregnant or breastfeeding. Prior to participating in the study, verbal and written informed consent from all participants were obtained. The study was approved by NUH's medical research ethics committee. This study was conducted in accordance with the Declaration of Helsinki.

\section{Procedure}

All measurements were taken by the same author (Ng T.S.). Participants came for one visit at NUH, which did not fall during the ovulatory phase of the female participants' menstrual cycle as pain inhibition is higher during ovulation. ${ }^{32}$ 
All participants completed demographic details and two questionnaires. This was followed by physical measurements taken in the same order in all participants: pressure pain threshold (PPT) (left tibialis anterior, left median nerve, right tibialis anterior, right median nerve, spinous process of fifth cervical vertebra C5), heat pain threshold, cold pressor test, heat pain threshold. Each triplicate measurement was separated by a 30 -second interval. The tests were performed in an air-conditioned laboratory with temperature set at $22{ }^{\circ} \mathrm{C}$.

\section{Measures}

\section{Pressure pain threshold}

PPT was measured using a pressure algometer with a probe size of $1 \mathrm{~cm}^{2}$ and application rate of $40 \mathrm{kPa} / \mathrm{s}$ (Somedic AB, Sweden). PPTs were measured at mid-cervical spine (C5), median nerve trunk at the elbow bilaterally and tibialis anterior muscle belly bilaterally. Subjects pressed a control button when the sensation changed from one of pressure alone to one of pressure and pain. At each test site, the mean of three readings taken was calculated.

\section{Cold pressor pain}

Participants' nondominant hand was first immersed in a bucket of water at room temperature $\left(22^{\circ} \mathrm{C}\right)$ for $1 \mathrm{~min}$. Following that, the same hand was immersed to just above the wrist in a recirculating water bath (Polyscience model 912, USA). Water temperature was kept constant at $2 \pm 0.2^{\circ} \mathrm{C}$. Participants were instructed to raise the dominant hand the moment cold sensation first became painful. The time that elapsed from immersing the nondominant hand into cold water to raising of the dominant hand was recorded as the cold pressor pain threshold. ${ }^{9}$ The nondominant hand was withdrawn when pain was intolerable (Figure 1). Cold pain tolerance was the time that the non-dominant hand was immersed in water minus the cold pressor pain threshold time. ${ }^{9}$ A ceiling of 120 seconds was imposed for pain tolerance to prevent tissue damage, thereafter this task was discontinued. Participants rated pain intensity every $15 \mathrm{~s}$ after hand immersion on the $10 \mathrm{~cm}$ visual analogue scale, until hand withdrawal or until the ceiling time was reached. Mean of all the pain intensity ratings was used for analysis.

\section{Test for CPM}

The test stimulus was contact heat delivered centrally over the mid-cervical spine using the thermotest system (Somedic AB, Sweden), a reliable tool for assessing thermal perception. ${ }^{33}$ Active surface area of the contact thermode was $25 \times 50 \mathrm{~mm}$. The temperature was preset to increase at a rate of $1^{\circ} \mathrm{C} / \mathrm{s}$ from a baseline of $30^{\circ} \mathrm{C}$. The maximum temperature was set at $50^{\circ} \mathrm{C}$. Participants pressed a patient-controlled switch when the heat sensation first became painful. ${ }^{34,35}$ This was the heat pain threshold measurement. The mean of triplicate readings of heat pain threshold (HPT) was used for analysis. The conditioning stimulus was cold water in the cold pressor pain test described above. Heat pain threshold was measured again 30 seconds (HPT30) after hand withdrawal in cold pressor test. CPM at 30 seconds was calculated by subtracting HPT from HPT30.

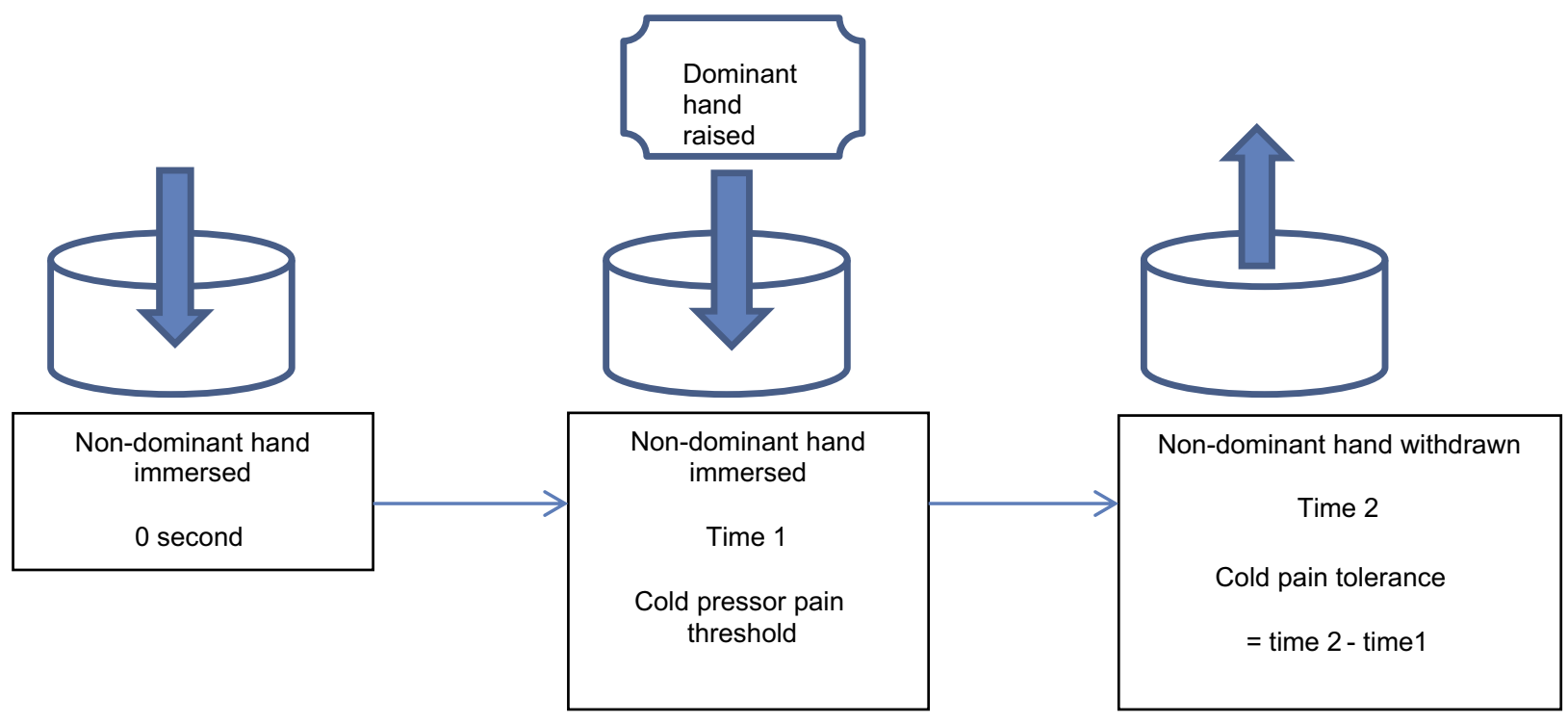

Figure I Measurement of cold pressor pain threshold and cold pain tolerance during the cold pressor test. 


\section{Questionnaires}

In order to determine the contribution of psychological factors to group differences in experimental pain responses, all participants completed the following questionnaires.

The New General Self-efficacy Scale ${ }^{36}$ was used to measure GSE. It is a unidimensional questionnaire comprising of 8 items scored on a 5 -point Likert scale ( $1=$ completely disagree, $3=$ don't know, $5=$ completely agree). The average of the responses is the GSE score, with GSE score of 5 being the maximum score. It has been validated and reliable, with a higher score indicating higher general self-efficacy. ${ }^{36}$

The 10-item Patient Health Questionnaire (PHQ-9) ${ }^{37}$ which inquired about depression within the last two weeks was used to assess depression. It is a reliable and valid tool for measuring depression. ${ }^{37}$ Response options are rated on a 4-point Likert scale (0-"not at all", 3-"nearly every day"). The sum of scores in the 9 items was used for analysis. The maximum possible score is 27. A total score of 10 or more is recommended as the cutoff point for clinically significant depression which corresponds to depression of at least moderate severity. ${ }^{37,38}$

\section{Statistical analysis}

Descriptive statistics were computed and normality of each variable was assessed. The distributions of cold pressor pain threshold and cold tolerance were skewed. Logarithm transformation was conducted to normalize the distribution of cold pressor pain threshold and cold pain tolerance. Wilcoxon signed-rank test was used to test group difference in depression score as transformation was ineffective. Repeated measures ANOVAs were used to compare variables with normal distribution in the matched groups, ie
PPTs, heat pain threshold, cold pressor pain threshold, cold pain tolerance, CPM. $\alpha$ was set at 0.05 .

Prior to mediational analysis of variables that were significantly different between both groups, Pearson's correlation analysis was performed to test the fulfillment of the conditions of mediation. Mediational analysis was then performed using linear regression.

\section{Results}

Thirty Chinese (mean age $35.5 \pm 11.3$ years, $50 \%$ female) and 30 Indian adults (mean age $35.3 \pm 9.6$ years, 50\% female) participated in this study. Both groups did not have depression and were similar in PHQ-9 score (Chinese: Median 2 Interquartile range (IQR)2; Indian: Median 2 IQR3, $\mathrm{Z}=-0.22, p=0.83$. GSE was significantly higher in Indians (Chinese:3.95 \pm 0.39 , Indian:4.24 $\pm 0.44, \mathrm{~F}$ $(1,29)=11.59, p=0.002$, effect size $=0.29)$.

\section{Pain measures}

PPTs, heat, cold and cold pressor pain thresholds in both groups were similar (Table 1). Chinese demonstrated greater cold pain tolerance than Indians. Average cold pain intensity was similar in both groups (Chinese: $7.3 \pm 1.4$, Indian: 7.4 \pm 1.1 , $\mathrm{F}(1,29)=0.19, p>0.05)$. Thirty seconds after hand withdrawal from the cold pressor test, CPM was less efficacious in Indians (Table 1). Seventy-three percent of Chinese and 43\% of Indians had positive values of CPM indicating pain inhibition.

\section{Mediational analysis}

As GSE was significantly higher in the Indian group, there was a possibility of mediation between GSE, race and cold tolerance as well as CPM. Pearson's correlational analysis

Table I Mean and standard deviation (SD) of pain thresholds, pain tolerance and CPM

\begin{tabular}{|c|c|c|c|c|}
\hline Variable & Chinese $(n=30)$ mean \pm SD & Indian $(n=30)$ mean $\pm S D$ & Statistic & $p$ \\
\hline PPT C5 & $347 \pm 8 \mathrm{l} \mathrm{kPa}$ & $360 \pm 74 \mathrm{kPa}$ & $\mathrm{F}=0.47$ & 0.50 \\
\hline PPT left median nerve & $302 \pm 79 \mathrm{kPa}$ & $303 \pm 60 \mathrm{kPa}$ & $\mathrm{F}=0.003$ & 0.96 \\
\hline PPT right median nerve & $309 \pm 78 \mathrm{kPa}$ & $306 \pm 43 \mathrm{kPa}$ & $F=0.09$ & 0.76 \\
\hline PPT left tibialis anterior & $544 \pm 128 \mathrm{kPa}$ & $559 \pm 124 \mathrm{kPa}$ & $F=0.29$ & 0.60 \\
\hline PPT right tibialis anterior & $565 \pm|4| \mathrm{kPa}$ & $577 \pm I 15 \mathrm{kPa}$ & $F=0.17$ & 0.69 \\
\hline Heat pain threshold & $43.2 \pm 3.4^{\circ} \mathrm{C}$ & $44.9 \pm 3,5^{\circ} \mathrm{C}$ & $F=3.38$ & 0.08 \\
\hline Cold pressor pain threshold & $6.56 \pm 3.66 \mathrm{~s}$ & $6.64 \pm 3,34 \mathrm{~s}$ & $F=0.032$ & 0.86 \\
\hline Cold pressor pain tolerance & $24.12 \pm 25.72 \mathrm{~s}$ & $18.91 \pm 22.50 \mathrm{~s}$ & $\begin{array}{l}F=5.05 \\
\text { Effect size } 0.15\end{array}$ & $0.03 *$ \\
\hline CPM & $1.7 \pm 2.7^{\circ} \mathrm{C}$ & $-0.6 \pm 3.7^{\circ} \mathrm{C}$ & $\begin{array}{l}F=7.6 \mathrm{I} \\
\text { Effect size } 0.2 \mathrm{I}\end{array}$ & $0.01 *$ \\
\hline
\end{tabular}

Note: $*_{p}<0.05$.

Abbreviation: s, seconds. 
Table 2 Correlational analysis between race, cold pain tolerance and conditioned pain modulation (CPM)

\begin{tabular}{|l|l|l|l|}
\hline & Race & Cold tolerance & CPM \\
\hline Race & & & \\
Pearson correlation & $\mathrm{I}$ & -0.30 & -0.34 \\
Significance $p$ & & 0.02 & 0.008 \\
\hline Cold tolerance & & 1 & \\
Pearson correlation & -0.30 & & 0.38 \\
Significance $p$ & 0.02 & & 0.003 \\
\hline
\end{tabular}

revealed that GSE was not significantly correlated with cold tolerance (correlation coefficient $-0.005 ; p=0.97$ ) and CPM (correlation coefficient $-0.10, p=0.46$ ). Hence, mediational analysis on GSE was not performed. Race, cold tolerance and CPM were significantly correlated (Table 2). Mediational analysis was performed on these three variables and revealed CPM as a mediator in the association between race and cold pain tolerance (Table 3, Figure 2).

\section{Discussion}

Our findings demonstrate racial difference in experimental pain responses. While the Chinese did not differ from Indians on pain threshold measures (pressure pain, heat pain, cold pressor pain) and pain intensity, they displayed significantly higher cold pain tolerance. Chinese also exhibited more efficacious CPM than Indians.

Pain tolerance is believed to reflect the affective-motivational dimension of pain whereas pain threshold and pain intensity ratings reflect the sensory-discriminative aspect of pain..$^{9,39,40}$ Our results show racial difference in pain tolerance but not in pain thresholds. This is consistent with previous findings. ${ }^{6}$ This finding may have clinical importance in that suprathreshold pain measures have been reported to be the most relevant experimental pain tasks to clinical pain. ${ }^{6}$ In Singapore, Indians have been found to have higher self-reported pain severity ratings than Chinese. ${ }^{29,30}$ Indians' lower pain tolerance found in this study, indicative of the affective-motivational dimension of pain, could contribute to the greater pain severity in this racial group. Pain tolerance is not independent of culture and psychosocial influence. ${ }^{10}$ In this study, psychological factors of depression and GSE were not associated with pain tolerance. Belief about appropriate pain response was not investigated in this study but was found to contribute to variance in pain tolerance in two different cultures. ${ }^{10}$ Cultural difference in pain belief systems could possibly play a part in the stronger affective-motivational dimension of pain and hence lower pain tolerance demonstrated in Indians.

CPM activates spinal-supraspinal-spinal pathways and appears to depend on endogenous opioid system, a descending pain-inhibitory system. ${ }^{4,41}$ In our study, Indians demonstrated less efficacious CPM than Chinese, indicating differences in endogenous pain inhibition between Indians and Chinese. The less efficacious CPM in healthy Indians in this study could be a possible mechanism to the greater pain severity reported in the Indian adults in Singapore.

As affective-motivational dimension of pain and CPM are under the influence of cortical structures, ${ }^{41-45}$ psychological factors are potential contributors to the racial difference in pain tolerance and CPM. However, assessment of psychological distress using depression did not reveal any difference between Chinese and Indians. The mean GSE score was reported to be 3.88 in healthy undergraduates and 4.22 in working adults. ${ }^{20}$ Although the GSE scores in both Chinese and Indians were comparable to scores in other healthy adults, ${ }^{20}$ GSE score was lower in Chinese than Indians in this study. Our results demonstrated that GSE, the belief of competence in dealing effectively with stressful situations, did not have any relationship with pain tolerance and CPM. Chinese reported lower GSE but exhibited higher cold pain tolerance and more efficacious CPM than Indians. In another aspect, Asian students reported lower GSE than non-Asian peers even though they were more successful in terms of academic achievements. ${ }^{21,46}$ Self-reported GSE could vary between races or nations ${ }^{21}$ and may not be associated with actual performance in stressful situations such as experimental pain and academic examinations. It is possible that other psychological factors such as pain

Table 3 Conditioned pain modulation (CPM) as a mediator between race and cold pain tolerance

\begin{tabular}{|l|l|l|l|l|l|}
\hline & B & Standard error & Beta & $\mathbf{t}$ & $\mathbf{p}$ \\
\hline Race & -2.85 & 3.39 & -0.11 & -0.84 & 0.41 \\
CPM & 2.09 & 1.01 & 0.27 & 2.06 & 0.04 \\
\hline
\end{tabular}

Note: Cold pain tolerance is the dependent variable. 


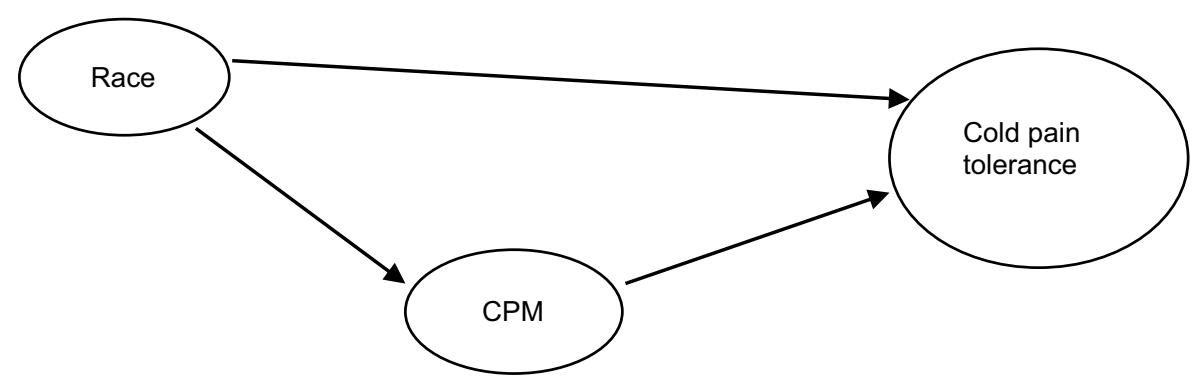

Figure 2 Conditioned pain modulation (CPM) is a mediator of race and cold pain tolerance.

catastrophizing and fear avoidance, and/or social factors such as socioeconomic status not measured in this study, could play a part in the observed racial differences in pain tolerance and CPM.

The mediational analysis in this study revealed CPM as a mediator in the relationship between race and cold pain tolerance. This suggests that the mechanism by which race affects cold pain tolerance could be contained in CPM. The higher cold pain tolerance in Chinese was mediated by endogenous pain inhibitory mechanism measured by CPM. Besides the role of central modulating system present in both pain tolerance and endogenous pain inhibition in CPM, there could possibly be a biological mechanism such as genetics to the racial difference in pain tolerance. Mu-opioid receptor gene (OPRM1) has been found to modulate pain perception and mediates the analgesic effects of opioid compounds in the central nervous system. ${ }^{47-49}$ The allele frequencies for the 118G allele of OPRM1 gene was significantly different between Chinese and Indian, and Indians have higher frequencies than Chinese. ${ }^{49,50}$ This OPRM118G genotype was associated with higher pain scores and morphine usage. ${ }^{49}$ The role of biological factors such as OPRM118G genotype in endogenous pain inhibition could possibly contribute to racial difference in pain tolerance. Endogenous pain inhibitory response measured by CPM, a mediator that contributes to the observed racial difference in pain tolerance, could possibly be the underlying mechanism to reported pain severity in clinical and the general population in Singapore. ${ }^{29,30}$

Clinicians need to be aware of the racial difference in pain tolerance and CPM between Chinese and Indian adults, especially those with persistent pain. A systematic review has shown that CPM is impaired in populations with chronic pain, highlighting the dysfunction of endogenous pain modulatory mechanisms in such populations. ${ }^{43}$ The underlying endogenous pain inhibitory mechanism could be less efficacious in Indians who experience pain, hence requiring a different approach to pain management. For example, pain management approach which targets the central modulatory system may be helpful for this race. Further study into the complex interaction between sociocultural, psychological and biological factors would help to further explain the mechanism of CPM and racial difference in pain severity.

There are a few limitations of this study. All the experimental pain tasks were acute, painful laboratory experiences which the participants had control over. The cold pressor pain intensity was recorded every $15 \mathrm{~s}$ and the average was used for analysis. This was one of the limitations of the study in that the number of times cold pressor pain intensity was recorded could vary between participants, depending on the tolerance of the participants. Results from these tasks may be less generalizable to the clinical populations. However, several studies have used these experimental pain procedures to predict clinical pain. ${ }^{51,52}$ Socioeconomic status such as income and educational level is reported to be associated with incidence of pain. ${ }^{53}$ Due to the lack of information on our participants' socioeconomic status, the impact of socioeconomic status on racial difference cannot be determined. The cross-sectional design of our study also did not allow a determination of the causal relationship between the observed racial differences and outcome such as pain severity. Nonetheless, the strengths of the present study had been demonstrated, ie the participants were age- and sex-matched, with care taken to collect data during a standardized phase of menstrual cycle of female participants.

\section{Conclusion}

Racial differences in cold pain tolerance and CPM were demonstrated between healthy Chinese and Indian adults. The higher cold pain tolerance in Chinese was mediated by endogenous pain inhibitory mechanism measured by CPM. 


\section{Acknowledgment}

Thanks to Professor Michele Sterling, The University of Queensland, for her support in this research.

\section{Disclosure}

The author reports no conflicts of interest in this work.

\section{References}

1. Porreca F. Nociceptors, the spinal dorsal horn, and descending modulation. In: I Tracey I, editor. IASP Refresher courses on pain management: 14th World Congress on Pain; 2012; Seattle, WA: IASP press. doi:10.1094/PDIS-11-11-0999-PDN

2. Lasch KE. Culture and pain. Pain Clin Updates. 2002;X(5):1-4.

3. Eisenhower A, Suyemoto K, Lucchese FMA, et al. "Which box should i check?": examining standard check box approaches to measuring race and ethnicity. Health Serv Res. 2014;49(3):1034-1055. doi:10.1111/1475-6773.12160

4. Campbell CM, Edwards RR. Ethnic differences in pain and pain management. Pain Manag. 2012;2(3):219-230. doi:10.2217/pmt.12.7

5. Green CR, Anderson KO, Baker TA, et al. The unequal burden of pain: confronting racial and ethnic disparities in pain. Pain Med. 2003;4(3):277-294. doi:10.1046/j.1526-4637.2003.03034.x

6. Kim HJ, Yanga GS, Greenspan JD, et al. Racial and ethnic differences in experimental pain sensitivity: systematic review and meta-analysis Pain. 2017;158:194-211. doi:10.1097/j.pain.0000000000000731

7. Rahim-Williams B, Riley JL, Williams AK, et al. A quantitative review of ethnic group differences in experimental pain response: do biology, psychology, and culture matter? Pain Med. 2012;13 (4):522-540. doi:10.1111/j.1526-4637.2012.01336.x

8. Gazerani P, Arendt-Nielsen L. The impact of ethnic differences in response to capsaicin-induced trigeminal sensitization. Pain 2005;117:223-229. doi:10.1016/j.pain.2005.06.010

9. Hsieh AY, Tripp DA, Ji LJ, et al. Comparisons of catastrophizing, pain attitudes, and cold-pressor pain experience between Chinese and European Canadian young adults. J Pain. 2010;11(11):1187-1194. doi:10.1016/j.jpain.2010.02.015

10. Nayak S, Shiflett SC, Eshun R, et al. Culture and gender differences in pain beliefs and the prediction of pain tolerance. Cross Cult Res. 2000;34:135-151. doi:10.1177/106939710003400203

11. Rowell LN, Mechlin B, Ji E, et al. Asians differ from non-Hispanic Whites in experimental pain sensitivity. Eur J Pain. 2011;15(7):764771. doi:10.1016/j.ejpain.2010.11.016

12. Watson PJ, Latif KR, Rowbotham DJ. Ethnic differences in thermal pain responses: a comparison of South Asian and White British healthy males. Pain. 2005;120:194-220. doi:10.1016/j.pain.2005.08.010

13. Morris MC, Walker L, Bruehl S, et al. Race effects on temporal summation to heat pain in youth. Pain. 2015;156:917-922. doi:10.1097/j.pain.0000000000000129

14. Goodin BR, Kronfli T, King CD, et al. Testing the relation between dispositional optimism and conditioned pain modulation: does ethnicity matter? J Behav Med. 2013;36:165-174. doi:10.1007/s10865012-9411-7

15. Campbell CM, France CR, Robinson ME, et al. Ethnic differences in diffuse noxious inhibitory controls. J Pain. 2008;9(8):759-766. doi:10.1016/j.jpain.2008.03.010

16. Cruz-Almeida Y, Sibille KT, Goodin BR, et al. Racial and ethnic differences in older adults with knee osteoarthritis. Arthritis Rheumatol. 2014;66:1800-1810. doi:10.1002/art.38620

17. Palit S, Kerr KL, Kuhn BL, et al. Examining emotional modulation of pain and spinal nociception in Native Americans: a preliminary investigation. Int J Psychophysiol. 2013;90:272-281. doi:10.1016/j. ijpsycho.2013.08.009
18. Riley JLIII, Cruz-Almeida Y, Glover TL, et al. Age and race effects on pain sensitivity and modulation among middle-aged and older adults. J Pain. 2014;15:272-282. doi:10.1016/j.jpain.2013.10.015

19. Bandura A. Self-efficacy: toward a unifying theory of beahvioral change. Psychol Rev. 1977;84:191-215.

20. Chen G, Gully SM, Eden D. General self-efficacy and self-esteem: towardtheoretical and empirical distinction between correlated selfevaluations. J Organiz Behav. 2004;25:375-395. doi:10.1002/(ISSN) 1099-1379

21. Scholz U, Dona BG, Sud S, et al. Is general self-efficacy a universal construct? Psychometric findings from 25 countries. Eur J Psychol Assess. 2002;18:242-251. doi:10.1027//1015-5759.18.3.242

22. Shwarzer R, Hahn A, Jerusalem A. Negative affect in East German migrants: longitudinal effects of unemployment and social support. Anxiety Stress Coping. 1993;6:57-60. doi:10.1080/ 10615809308249532

23. Taylor WJ, Dean SG, Siegert RJ. Differential association of general and health self-efficacy with disability, health-related quality of life and psychological distress from musculoskeletal pain in a crosssectional general adult population survey. Pain. 2006;125:225-232. doi:10.1016/j.pain.2006.05.023

24. Nahman-Averbuch H, Nir RR, Sprecher E, Yarnitsky D. Psychological factors and conditioned pain modulation: a meta-analysis. Clin J Pain. 2016;32(6):541-554. doi:10.1097/AJP.0000000000000296

25. Axford J, Heron C, Ross F, Victor CR. Management of knee osteoarthritis in primary care: pain and depression are the major obstacles. J Psychosom Res. 2008;64:461-467. doi:10.1016/j.jpsychores.2007.11.009

26. Euteneuer F, Schwarz MJ, Hennings A, et al. Depression, cytokines and experimental pain: evidence for sex-related association patterns. J Affect Disord. 2011;131(1-3):143-149. doi:10.1016/j. jad.2010.11.017

27. Thompson T, Correll CU, Gallop K, Vancampfort D, Stubbs B. Is pain perception altered in people with depression? A systematic review and meta-analysis of experimental pain research. $J$ Pain. 2016;17:1257-1272. doi:10.1016/j.jpain.2015.12.006

28. Ahn H, Weaver M, Lyon D, Choi E, Fillingim RB. Depression and pain in Asian Americans and Whites with knee osteoarthritis. J Pain. 2017;18(10):1229-1236. doi:10.1016/j.jpain.2017.05.007

29. Chan C, Malhotra C, Do YK, et al. Self-reported pain severity among multiethnic older Singaporeans: does adjusting for reporting heterogeneity matter? Eur J Pain. 2011;15:1094-1099. doi:10.1016/j. ejpain.2011.05.006

30. Tan EC, Lim Y, Teo YY, et al. Ethnic differences in pain perception and patient-controlled analgesia usage for postoperative pain. J Pain. 2008;9(9):849-855. doi:10.1016/j.jpain.2008.04.004

31. Yosipovitch G, Meredith G, Chan YH, et al. Do ethnicity and gender have an impact on pain thresholds in minor dermatologic procedures? A study on thermal pain perception thresholds in Asian ethnic groups. Skin Res Tech. 2004;10:38-42. doi:10.1111/j.16000846.2004.00051.x

32. Tousignant-Laflamme Y, Marchand S. Excitatory and inhibitory pain mechanisms during the menstrual cycle in healthy women. Pain. 2009;146:47-55. doi:10.1016/j.pain.2009.06.018

33. Palmer ST, Martin DJ. Thermal perception thresholds recorded using method of limits change over brief time intervals. Somatosen Mot Res. 2005;22:327-334. doi:10.1080/08990220500420731

34. Chien A, Eliav E, Sterling M. Hypoaesthesia occurs with sensory hypersensitivity in chronic whiplash- Further evidence of a neuropathic condition. Man Ther. 2009;14:138-146. doi:10.1016/j. math.2007.12.004

35. Sterling M, Jull G, Vicenzino B, et al. Sensory hypersensitivity occurs soon after whiplash injury and is associated with poor recovery. Pain. 2003;104:509-517.

36. Chen G, Gully SM, Eden D. Validation of a new general self-efficacy scale. Organiz Res Methods. 2001;4(1):62-83. doi:10.1177/ 109442810141004 
37. Kroenke K, Spitzer RL, Williams JB. The PHQ-9: validity of a brief depression severity measure. J Gen Intern Med. 2001;16(9):606-613. doi:10.1046/j.1525-1497.2001.016009606.x

38. Kroenke K, Spitzer RL, Williams JB, et al. The patient health questionnaire somatic, anxiety, and depressive symptoms scales: a systematic review. Gen Hosp Psychiat. 2010;32:345-359. doi:10.1016/j. genhosppsych.2010.03.006

39. Edwards RR, Fillingim RB. Ethnic differences in thermal pain responses. Psychosom Med. 1999;61(3):346-354.

40. Price DD. Psychophysical measurement of normal and abnormal pain processing. In: Boivie J, Hansson P, Lindblom U, editors. Touch, Temperature and Pain in Health and Disease. Mechanisms and Assessments, Progress in Pain Research and Management. Vol. 3. Seattle, WA: IASP press; 1994:3-25.

41. Staud R. Abnormal endogenous pain modulation is a shared characteristic of many chronic pain conditions. Expert Rev Neurother. 2012;12(5):577-585. doi:10.1586/ern.12.41

42. Auvray M, Myin E, Spence C. The sensory-discriminative and affective-motivational aspects of pain. Neurosci Biobehav Rev. 2010;34 (2):214-223. doi:10.1016/j.neubiorev.2008.07.008

43. Lewis GN, Rice DA, McNair PJ. Conditioned pain modulation in populations with chronic pain: a systematic review and meta-analysis. J Pain. 2012;13(10):936-944. doi:10.1016/j.jpain.2012.07.005

44. Rainville P. Brain mechanisms of pain affect and pain modulation. Curr Opin Neurobiol. 2002;12(2):195-204.

45. van Wijk G, Veldhuijzen DS. Perspective on diffuse nociceptive inhibitory controls as a model of endogenous pain modulation in clinical pain syndromes. J Pain. 2010;11(5):408-419. doi:10.1016/j.jpain.2009.10.009

46. Yan W, Gaier EL. Causal attributions for college success and failure: an Asian Amerian comparison. $J$ Cross-Cultural Psychol. 1994;25:146-158. doi:10.1177/0022022194251009
47. Fillingham RB, Kaplan L, Staud R, et al. The A118G single nucleotide polymorphism of the mu-opioid receptor gene (OPRM1) is associated with pressure pain sensitivity in humans. J Pain. 2005;6 (3):159-167. doi:10.1016/j.jpain.2004.11.008

48. Sia AT, Lim Y, Lim ECP, et al. A118G single nucleotide polymorphism of human [mu]-opioid receptor gene influences pain perception and patient-controlled intravenous morphine consumption after intrathecal morphine for postcesarean analgesia. Anesthesiology. 2008;109(3):520-526. doi:10.1097/ALN.0b013e318182af21

49. Tan EC, Lim ECP, Teo YY, et al. Ethnicity and OPRM variant independently predict pain perception and patient-controlled analgesia usage for post-operative pain. Mol Pain. 2009;5(32). doi:10.1186/ 1744-8069-1185-1132

50. Tan EC, Tan CH, Karupathivan U, et al. Mu opioid receptor gene polymorphisms and heroin dependence in Asian populations. Neuroreport. 2003;14(4):569-572. doi:10.1097/01.wnr.0000061020. 47393.fc

51. Edwards RR, Ness TJ, Weigent DA, et al. Individual differences in diffuse noxious inhibitory controls (DNIC): association with clinical variables. Pain. 2003;106(3):427-437.

52. Granot M, Lowenstein L, Yarnitsky D, et al. Postcesarean section pain prediction by preoperative experimental pain assessment. Anesthesiol. 2003;98:1422-1426. doi:10.1097/00000542-200306 000-00018

53. Dorner TE, Muckenhuber J, Stronegger WJ, et al. The impact of socioeconomic status on pain and the perception of disability due to pain. Eur $J$ Pain. 2011;15(1):103-109. doi:10.1016/j.ejpain.2010.05.013
Journal of Pain Research

\section{Publish your work in this journal}

The Journal of Pain Research is an international, peer reviewed, open access, online journal that welcomes laboratory and clinical findings in the fields of pain research and the prevention and management of pain. Original research, reviews, symposium reports, hypothesis formation and commentaries are all considered for publication. The manuscript management system is completely online and includes a very quick and fair peer-review system, which is all easy to use. Visit http:// www.dovepress.com/testimonials.php to read real quotes from published authors. 